\title{
The rRNA operons of Mycobacterium smegmatis and Mycobacterium tuberculosis: comparison of promoter elements and of neighbouring upstream genes
}

\author{
Jorge A. Gonzalez-y-Merchand, ${ }^{1,2}$ M. Joseph Colston' and Robert A. Cox ${ }^{1}$
}

Author for correspondence: Robert A. Cox. Tel: +44 1819593666 . Fax : +44 1819064477.

\footnotetext{
1 Division of Mycobacterial Research, National Institute for Medical Research, The Ridgeway, Mill Hill, London NW7 1AA, UK

2 Departamento de Microbiologia, Escuela Nacional de Ciencias Biologicas, IPN, Ap. Postal 4-870, 06400 Mexico DF, Mexico
}

\begin{abstract}
Mycobacterium smegmatis has two rRNA (rrn) operons designated $r r n A_{f}$ and $r^{r n B_{f}}$. Appropriate restriction fragments of genomic DNA containing sequences immediately upstream from the 165 rRNA genes were cloned. We now report the nucleotide sequence of 552 bp upstream from the 5 -end of the Box $A_{L}$ antitermination element of the leader region of the $\boldsymbol{r r n A}_{\mathrm{f}}$ operon. The 5 -end of this segment of DNA was found to comprise 113 codons of an ORF encoding a protein which is significantly similar to UDP- $N$-acetylglucosamine 1-

carboxyvinyl-transferase (EC 2.5.1.7), which is important to cell wall synthesis. A homologous ORF is located immediately upstream from the single rrn ( $\left(r n A_{s}\right)$ operons of Mycobacterium tuberculosis and Mycobacterium leprae. Primer-extension analysis of the RNA fraction of $\boldsymbol{M}$. smegmatis revealed four products which were related to transcription start points; the $\mathrm{rrnB}_{\mathrm{f}}$ operon appears to have a single promoter whereas the $\mathbf{r n A}_{\mathrm{f}}$ operon has three (P1, P2 and P3). Analysis of $M$. tuberculosis RNA revealed two products corresponding to transcripts directed by promoters homologous with P1 and P3 of the $r r n A_{f}$ of $M$. smegmatis. Thus, the promoter and upstream regions of the $r m A_{f}$ operon of $M$. smegmatis and the $r \mathbf{r n A}_{\mathbf{s}}$ operon of $M$. tuberculosis are homologous. The presence of $\mathbf{P 2}$ in $\boldsymbol{M}$. smegmatis and its absence from $\boldsymbol{M}$. tuberculosis is attributable to insertions/deletions of $97 \mathrm{bp}$.
\end{abstract}

Keywords: pathogenic/non-pathogenic mycobacteria, rRNA operons, promoter activities, cell wall synthesis, UDP- $N$-acetylglucosamine 1-carboxyvinyltransferase

\section{INTRODUCTION}

The two major mycobacterial pathogens, Mycobacterium tuberculosis and Mycobacterium leprae are characterized by the ability to grow slowly within host cells. The mechanisms which these organisms use to control their growth rate are not well understood. There is a clear relationship between rates of growth, protein biosynthesis and the production of ribosomes (Bremer \& Dennis, 1987; Winder \& Rooney, 1970). An understanding of the way in which ribosome synthesis is regulated in the slowgrowing mycobacteria would further our understanding of cell proliferation. In addition, by comparing the

Abbreviation: UNACGCT, UDP-N-acetylglucosamine 1-carboxyvinyl-transferase.

The EMBL accession numbers for the sequences reported in this paper are X87943 and X87944. regulation of ribosome synthesis in the pathogenic slowgrowing species with that in fast-growing mycobacteria, most of which are non-pathogenic, we are likely to gain new insights into the evolution of growth-rate control in these two phylogenetically distinct groups.

$M$. leprae and $M$. tuberculosis each have a single rRNA ( $r r n)$ operon (Liesack et al., 1990; Sela \& Clark-Curtiss, 1991; Kempsell et al., 1992; Suzuki et al., 1988). The single $r$ rn operons of the slow-growers studied are sufficiently closely related in both their primary and secondary structures to be regarded as members of a family, described as $r r n A_{\mathrm{s}}$ operons (the subscript 's' denotes slow-growers) by Ji et al. (1994c). In contrast to slowgrowers, fast-growing mycobacteria have two $\mathrm{rrn}$ operons (Bercovier et al., 1986). The two $r r n$ operons of a representative fast-grower, Mycobacterium smegmatis, were investigated previously (Ji et al., 1994c). Based on sequence analysis, one of the operons was found to be 
(a) M. smegmatis $r n A_{f}$ operon

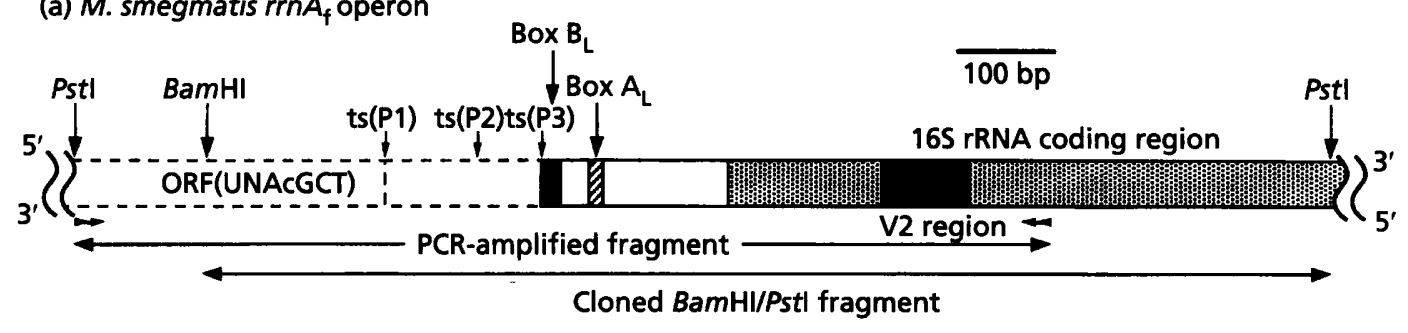

(b)

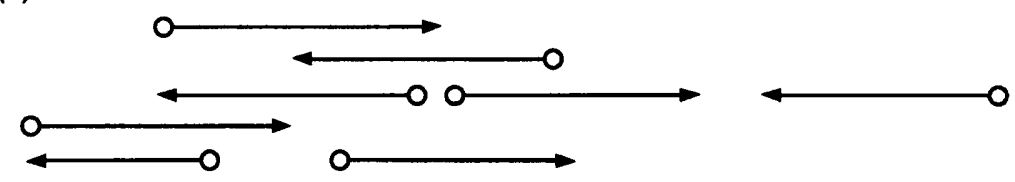

(c) M. tuberculosis $r$ rnA $A_{\mathrm{s}}$ operon

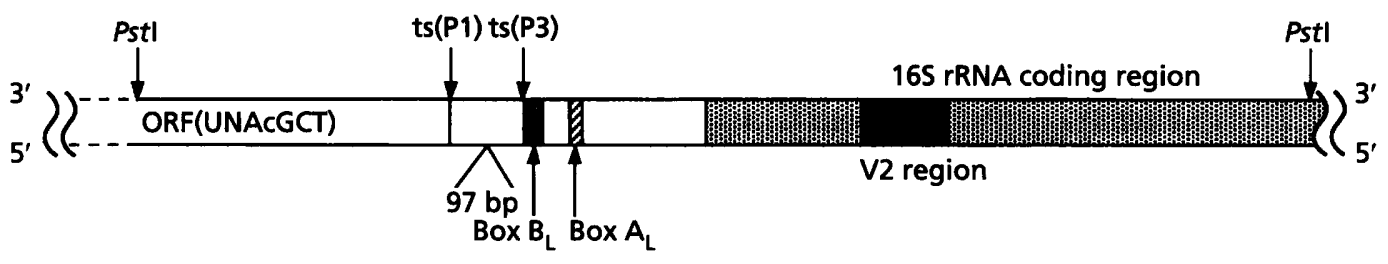

Fig. 1. Scope of this investigation. (a) Part of the $r r n A_{f}$ operon of $M$. smegmatis. The nucleotide sequence downstream from the Box $B_{1}$ antitermination element was reported previously (Ji et al., 1994C). The nucleotide sequence of the $\mathrm{V} 2$ region of the 16S rRNA (for definition see Kempsell et al., 1992) serves as a signature sequence that is useful for identifying the species. This report concerns the nucleotide sequence of the region indicated by broken lines; that is, upstream from the Box $A_{L}$ element to the Pstl site. Sequence data were obtained after cloning the BamHI/(downstream) Pstl fragment, and after amplifying and cloning the region between the upstream Psti and position 357 of the 16S rRNA coding region. The primers used for amplification are shown by short horizontal arrows. The results reveal the identity of the promoters that correspond to transcription start sites ts(P1), ts(P2) and ts(P3), and also the presence of an ORF in the position shown. (b) Sequencing strategy. Open circles indicate the binding sites of the primers used in the sequencing reaction, and the length of the arrows represent the region of sequence identified by means of the primer. (c) Part of the $r r n A_{s}$ operon of $M$. tuberculosis. The data (see Kempsell et al., 1992) provide a frame of reference for (a). The segments of the operon shown in (a) and (c) are related by insertions/deletions of $97 \mathrm{bp}$ in the region indicated by the open triangle (see text). ts(P1) and ts(P3) indicate the transcription start sites identified by Verma et al. (1994) and by primerextension studies as described below. In both (a) and (c) the ORF corresponds to part of the gene encoding a protein significantly similar to UNACGCT.

closely related to the $\operatorname{rrn} A_{\mathrm{s}}$ operon of slow-growers and was designated $r r n A_{\mathrm{f}}$ (the subscript ' $\mathrm{f}$ ' denotes fastgrowers). The other $M$. smegmatis operon was designated $r r n B_{\mathrm{f}}$ (Ji et al., 1994c); this operon appeared to be more distantly related to the $\operatorname{rrn} A_{\mathrm{s}}$ operon of slow-growers.

We have now cloned and sequenced the regions of the $r r n A_{\mathrm{f}}$ and $r r n B_{\mathrm{f}}$ operons of $M$. smegmatis upstream from the putative antitermination element, Box $A_{L}$, which is highly conserved between all of the mycobacterial $r r n$ operons (Ji et al., 1994c). We find that the $r r n A_{\mathrm{f}}$ and the $\operatorname{rrn} A_{\mathrm{s}}$ operons have similar sequences in this region, confirming our earlier hypothesis concerning the relatedness of these two operons. In addition, we have used RNA extracted from both $M$. smegmatis and $M$. tuberculosis to compare the promoter regions of the two species using primer extension. The RNA fraction of $M$. smegmatis revealed at least four transcription start points; the $r r n B_{\mathrm{f}}$ operon appears to have a single promoter, while the $\operatorname{rrn} A_{\mathrm{f}}$ operon has at least three. The single $M$. tuberculosis $\operatorname{rrn} A_{\mathrm{s}}$ operon appears to have two promoter elements. Thus the slow-growing mycobacteria not only have a reduced number of $r r n$ operons, but also have a reduced number of regulatory elements involved in their transcription. Intriguingly, we also found that both $\operatorname{rrn} A_{\mathrm{f}}$ and $\operatorname{rrn} A_{\mathrm{s}}$ have a promoter, $\mathrm{P} 1$, which is located within a gene, which terminates $427 \mathrm{bp}$ upstream of the $16 \mathrm{~S}$ rRNA coding region. This gene encodes a protein that is significantly similar to an enzyme involved in bacterial cell wall synthesis suggesting that the production of the enzyme and transcription of the rRNA are linked.

\section{METHODS}

Materials. Restriction endonucleases and T4 ligase were from Boehringer Mannheim. Sequenase (USB) sequencing kit was supplied by Cambridge Biosciences. $\left[{ }^{35} \mathrm{~S}\right] \mathrm{dATP} \alpha \mathrm{S}$ was from Amersham. GeneClean kit was from Bio101. The original TA cloning kit for PCR cloning was purchased from Invitrogen. The avian myeloblastosis virus (AMV) reverse transcriptase 


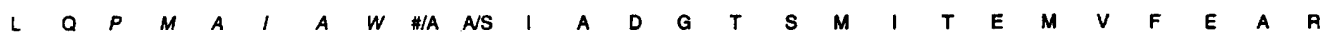

M.sm(Af) i CTG CAG ecg atg get ate get ttg nCG GCG ATC GCC GAC GGS ACG TCG ATG ATC ACC GAG AaC GTG TTC GAG GCG CGC 78

M.UU(A) CAS S CAG CCG ATG GCT ATC GCT TTG GCG TCG ATC GCC GAC GGC ACA TCG ATG ATC ACG GAG AaC GTG TTC GAG GCG CGG

\section{$\begin{array}{lllllllllllllllllllllllllll}F & R & F & V & E & E & M & I & A & L & G & A & D & A & R & T & D & G & H & H & A & V & V & R & G & \text { M }\end{array}$}

M.Sm(Af) 79 TTC CGG TTC GTC GAG GAG ATG ATC CGG CTC GGC GCC GAC GCC CGT ACC GAC GGA CAC CAC GCC GTG GTG CGG GGG ATC 156 M.tU(As) TTC CGC TTC GTT GAA GAG ATG ATC CGG CTC GGT GCA GAC GCT CGG ACC GAC GGG CAC CAC GCC GTG GTG CGG GGC CTC

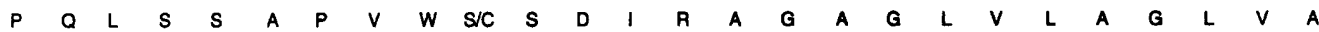

M.Sm(Af) 157 SCG CAG TTG TCG AGC GCA CCC GTG TGG TCG TCG GAC ATC CGG GCC GGT GCC GGC CTG GTG CTC GCC GGC CTG GTC GCC 234 M.tU(As) CCG CAG CTG TCG AGC GCT CCG GTG TGG TGT TCG GAC ATC CGT GCC GGG GCC GGC TTG GTG CTG GCG GGG CTC GTT GCC

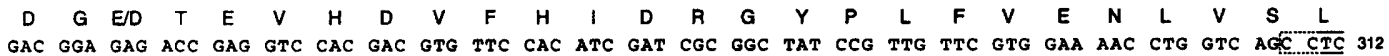
M.sm(Af) 235 GAC GGA GAG ACC GAG GTC CAC GAC GTG TTC CAC ATC GAT CGC GGC TAT CCG TTG TTC GTG GAA AAC CTG GTC AGC CTC
M.tu(A $\left(A_{5}\right)$ GAC GGC GAC ACC GAG GTC CAC GAT GTA TTC CAC ATC GAT CGC GGA TAT CCG TTG TTC GTG GAG AAC CTG GTG AG CGTC

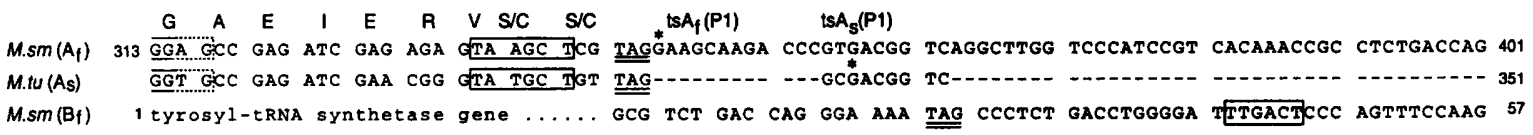
$\mathrm{tsB}_{\mathrm{f}}(\mathbf{P} 1)$ * $\operatorname{ss}_{f}(\mathbf{P} 2)$

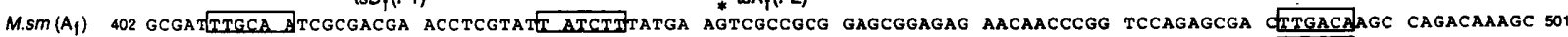

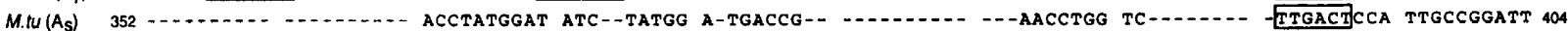
M.Sm $\left(B_{f}\right) \quad 58$ GaCG $\mathrm{tsA}_{\mathrm{f}}(\mathrm{P} 3) /$

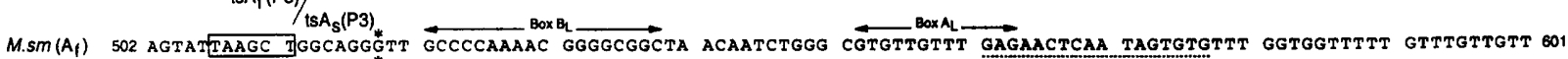
M.tu(A $\left.A_{s}\right) 405$ TGTATPAGAC JGGCAGGGTT GCCCCGAAGC GG-GCGG-AA ACAAGCAAGC -GTGTTGTTT GAGAACTCAA TAGTGTGTTT GGTGGTTTCA CATTTTTGTT 501

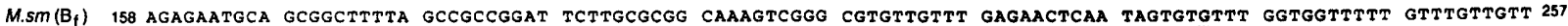

Fig. 2. Nucleotide sequences of the regions of the $M$. smegmatis (M.sm) genome upstream from the Box $A_{L}$ elements of the $r r n A_{f}$ and $r r n B_{f}$ operons and comparison with the $r r n A_{s}$ operon of $M$. tuberculosis (M.tu) [The sequence in Kempsell et al. (1992) was re-determined and several errors were identified. The principal correction is the deletion of positions 73-83 from their sequence. The corrected version is given above]. The deduced amino acid sequences encoded by the putative genes for UNACGCT (see Fig. 1) are given using the one-letter code. A single letter is given where the same amino acid is encoded by both M.sm and M.tu species, otherwise the amino acid for M.sm is given first; an italic letter indicates that the identity of the amino acid in the $M$. smegmatis gene is provisional because it is inferred from the sequence of the PCR primer. The Pstl and BamHI sites are underlined and the TAG codons at the 3'-ends of coding regions are doubly underlined. Putative promoter elements ( -35 and -10 boxes) are framed; uncertainty in the identity of -35 boxes is indicated by broken lines. $M . \operatorname{sm}\left(A_{4}\right)$, etc., $r r n A_{f}$ operon of $M$. smegmatis, etc.; $G^{*}$, transcription start points inferred from primer-extension products (see Fig. 4). ts $A_{f}(P 1)$, etc., transcription start site directed by the P1 promoter of the $r r n A_{f}$ operon, etc. The sequence of the $r r n B_{f}$ operon of $M$. smegmatis was also established (see also Fig. 4) and is in agreement with the data of Predich et al. (1995). -, Deletion; N, nucleotide of unknown identity; \#, amino acid of unknown identity; dotted lines indicate where the oligonucleotide primer, used for primer-extension studies, annealed.

primer-extension system was supplied by Promega. Oligonucleotides primers were prepared with an automated DNA synthesizer (model 370A, Applied Biosystems).

Bacterial strains, media and vector. $M$. smegmatis NCTC 8159 (National Collection of Type Cultures) was maintained on Löwenstein-Jensen slopes and grown to exponential phase in Lemco Broth containing $0.1 \%$ Tween 80 for use in primerextension studies. $M$. tuberculosis $\mathrm{H} 37 \mathrm{Rv}$ was grown in Middlebrook medium. Epicurian Coli XL1-Blue competent cells (Stratagene) were used for transformation with the recombinant phagemid Bluescript SK (pSK) (Stratagene) and grown on LB medium. $M$. tuberculosis DNA was given by Dr E. Davis, National Institute for Medical Research, Mill Hill, London, UK.

Isolation of DNA. Plasmid DNA was isolated by standard methods exactly as described previously by Ji et al. (1994c). Genomic DNA from $M$. smegmatis was isolated by a novel method (Gonzalez-y-Merchand et al., 1996). Briefly, the cells were suspended in $6 \mathrm{M}$ guanidinium chloride and then kept at $65^{\circ} \mathrm{C}$ for $10 \mathrm{~min}$. The DNA was then precipitated and resuspended in TE buffer by conventional means.

Isolation of RNA. Exponential-phase cells (100 ml culture) were collected and resuspended in $1 \mathrm{ml}$ guanidinium buffer $(6 \mathrm{M}$ guanidinium chloride, $0 \cdot 1 \%, \mathrm{v} / \mathrm{v}$, Tween $80,10 \mathrm{mM}$ EDTA, $1 \mathrm{mM} 2$-mercaptoethanol) and left at $-20^{\circ} \mathrm{C}$ for $15 \mathrm{~min}$. The suspension was added to a half of the volume of heat-sterilized $0.15 \mathrm{~mm}$ glass beads contained in a $2 \mathrm{ml}$ screw-cap microcentrifuge tube. Mycobacteria were ruptured by 3 pulses each of $1 \mathrm{~min}$, on the Mini-BeadBeater device (Biospec Products). Debris and beads were sedimented by centrifugation $(10000 \mathrm{~g}$ for $3 \mathrm{~min}$ ), and the cleared lysate was retained. The pellet of beads and mycobacterial residues was briefly re-extracted on the BeadBeater ( $30 \mathrm{~s}$ pulse) with $300 \mu \mathrm{l}$ fresh guanidinium buffer 
and the resulting extract was pooled with the first. The lysate was extracted three times with 2 vols chloroform/3-methyl-1butanol $(24: 1, \mathrm{v} / \mathrm{v})$. RNA was precipitated by the dropwise addition of $0.5 \mathrm{vol}$. ethanol and then redissolved in the appropriate volume of MOPS buffer.

Primer extension. The oligonucleotide primer $5^{\prime}$ CACACTATTGAGTTCTC3' has a target site which is present in all three of the $r r n$ operons studied (see Fig. 2). This primer was endlabelled with $\left[\gamma^{32} \mathrm{P}\right] \mathrm{ATP}$ by means of T4 polynucleotide kinase, and the primer extension was carried out using the AMV reverse transcriptase primer-extension system. Briefly, the ${ }^{32} \mathrm{P}$ labelled primer ( $100 \mathrm{fmol})$ was added to a mixture of $5 \mu \mathrm{l}$ water containing $24 \mu \mathrm{g}$ total RNA and $5 \mu \mathrm{l}$ AMV primer extension (PE) $2 \times$ buffer $(100 \mathrm{mM}$ Tris, $100 \mathrm{mM} \mathrm{KCl,} 20 \mathrm{mM} \mathrm{MgCl}$, $20 \mathrm{mM}$ DTT, $2 \mathrm{mM}$ each dNTP, $1 \mathrm{mM}$ spermidine). The mixture was annealed at $52{ }^{\circ} \mathrm{C}$ for $30 \mathrm{~min}$ and left to cool in air at room temperature for $10 \mathrm{~min}$; then $5 \mu \mathrm{l} \mathrm{PE} 2 \times$ buffer, $1.4 \mu \mathrm{l}$ $40 \mathrm{mM}$ sodium pyrophosphate, and 1 unit AMV reverse transcriptase were added to each reaction. The reaction mixture was incubated at $42{ }^{\circ} \mathrm{C}$ for $1 \mathrm{~h}$, extracted once with phenol/ chloroform, ethanol-precipitated, and washed with $70 \%$ $(\mathrm{v} / \mathrm{v})$ ethanol. The extension products were separated on a $8 \%$ (w/v) polyacrylamide/urea gel and visualized by autoradiography.

Genomic DNA cloning. The products of the digestion with $P_{s t} \mathrm{I}$, or double digestion with $B a m \mathrm{HI}$ and $P_{s t} \mathrm{I}$ restriction endonucleases, of genomic DNA were separated by $1 \%(\mathrm{w} / \mathrm{v})$ agarose gel electrophoresis. A $3.2 \mathrm{kbp}$ Pst I or $1.2 \mathrm{kbp}$ Bam HI/Pst $\mathrm{I}$ fraction was recovered from the gel using glass milk (Vogelstein \& Gillespie, 1979). The BamHI/PstI fraction was ligated into $\mathrm{pSK}$ (which was previously digested with Pst I and Bam HI). The PstI fraction was ligated into pSK previously digested with PstI. In each case the molar ratio of vector to insert was $1: 1$.

PCR. Bacterial DNA (1-100 ng) was subjected to PCR (Saiki et al., 1988) as described previously (Ji et al., 1994c). The relevant gene fragment encoding 114 amino acids of UDP-Nacetylglucosamine 1-carboxyvinyl-transferase (UNAcGCT) (EC 2.5.1.7), the promoter region of the $\operatorname{rrn} A_{\mathrm{f}}$ and $r r n A_{\mathrm{s}}$ operons, the $5^{\prime}$-ends of the leader regions of their precursorRNA (pre-rRNA) and the $5^{\prime}$-region of the 16 S ribosomal DNA was synthesized using the primer combination of JG7 (5'CTGCAGCCGATGGCTATCGCTTTG3') and RAC8 (5'CACTGGTGCCTCCCGTAGG3'). The target for primer JG7 is the sequence complementary to positions $1-24$ of $M$. tuberculosis (Fig. 2). The target for RAC8 is positions 339-357 of the 16S rRNA coding region (see Kempsell et al., 1992). Amplification was achieved as described previously (Ji et al., 1994c).

PCR cloning. The products of PCR were separated and recovered from the gel as described above. The PCR products were ligated into PCR II and transformed into One Shot (INV $\alpha \mathrm{F}^{\prime}$ ) competent cells as specified in the manual of the original TA cloning kit. The molar ratio of vector to insert was kept at $1: 1$.

Sequencing of dsDNA. DNA sequences were determined by the dideoxy chain-termination procedure using $\left[{ }^{35} \mathrm{~S}\right] \mathrm{dATP} \alpha \mathrm{S}$, as described by Ji et al. (1994c) using appropriate primers as indicated in Fig. 1(b).

Alignment of sequences. Computer-aided analysis of the alignment of nucleotide sequences of the gene encoding UNAcGCT and promoter regions was achieved by means of the BLAST program (Altschul et al., 1990). The database searches were carried out using the UK Human Genome Mapping Project computing services (Rysavy et al., 1992).

\section{RESULTS AND DISCUSSION}

The scope of this study is illustrated in Fig. 1. Previously, we reported aspects of both the primary and the secondary structure of the rrn operons and the secondary structure of their transcripts (pre-RNA) for $M$. tuberculosis and $M$. leprae and several other slow-growing mycobacteria (Kempsell et al., 1992; Ji et al., 1994a, b). In this study we report the upstream sequence of the $M$. smegmatis $\operatorname{rrn} A_{\mathrm{f}}$ operon and compare the promoter elements of the two $M$. smegmatis operons with those of the single $M$. tuberculosis $\operatorname{rrn} A_{\mathrm{s}}$ operon.

\section{Nucleotide sequences of the upstream regions}

The strategies described in Fig. 1 were used to establish the nucleotide sequence upstream from the Box $A_{L}$ motif of the $r r n A_{\mathrm{f}}$ operon. As shown in Fig. 2, $342 \mathrm{bp}$ of an ORF were identified. A search of the databases (see Methods) revealed that the amino acid sequence inferred

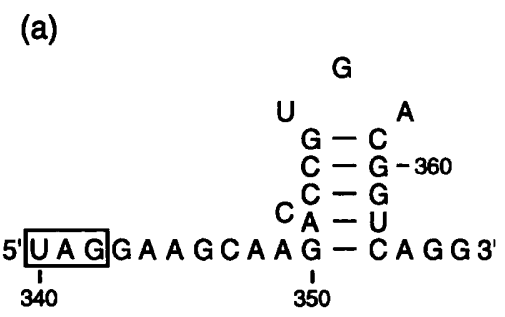

(b)

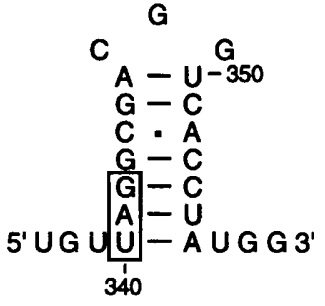

(c)

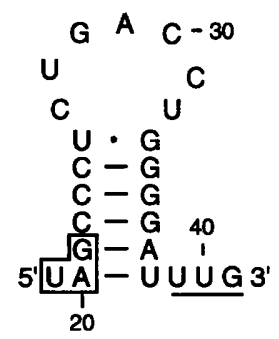


M. $s m$

T C G A 12 2 T C G A

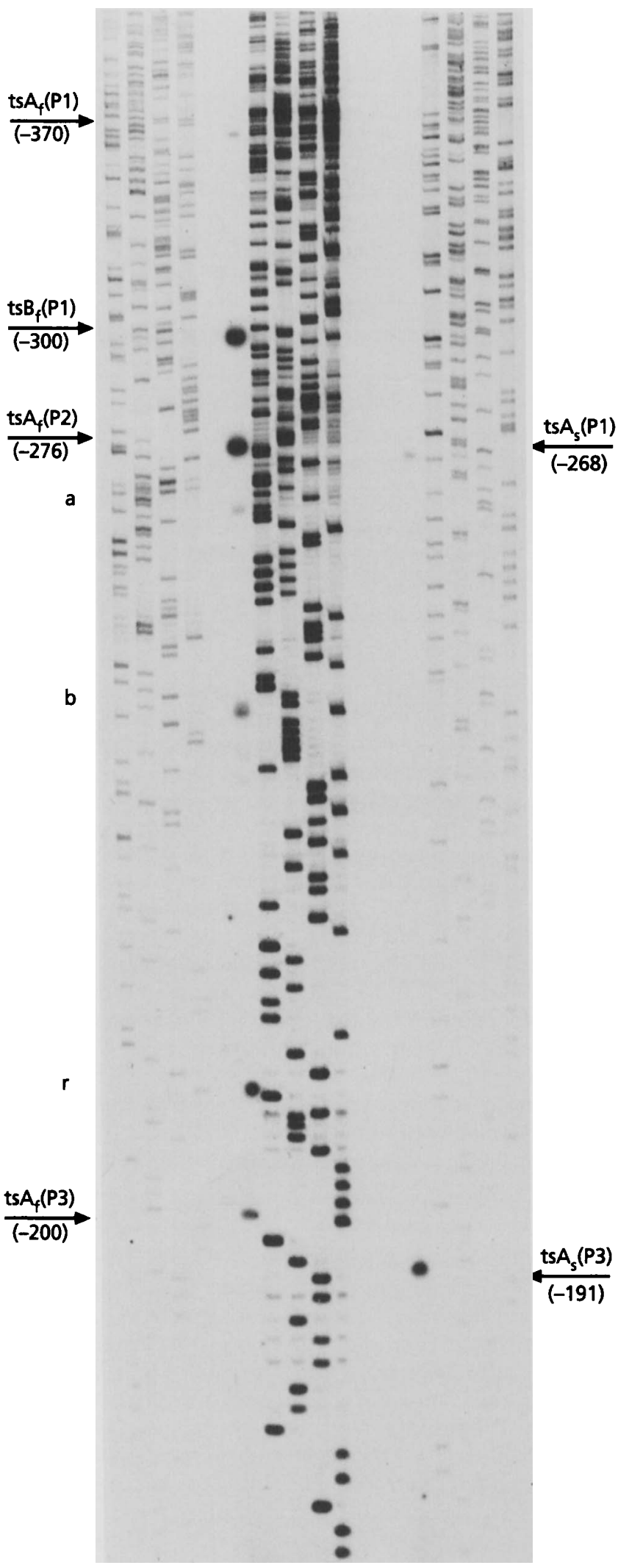

Fig. 4. Comparison of the locations of the $5^{\prime}$-ends of pre-rRNA of $M$. smegmatis and $M$. tuberculosis. The $5^{\prime}$-ends of pre-rRNAs were located by primer extension (see Methods) using 32plabelled primer whose target sites overlap the Box $A_{L}$ elements (see Fig. 2). Lanes T, C, G and A are products of sequencing reactions carried out using the same primer as mentioned above and a recombinant phagemid containing an appropriate inserted $r r n$ sequence. The sequencing reactions for the $r r n A_{f}$ and $r r n B_{f}$ operons of $M$. smegmatis and the $r r n A_{s}$ operon of $M$. tuberculosis are shown from left to right, respectively. The transcription start (ts) sites inferred from the products, ts $A_{4}(P 1)$, etc., indicate the operon and the promoter (see Fig. 2), and the number in parentheses signifies the distance upstream from the 5 '-end of the 16S rRNA gene. $a$ and $b$, Products which were not correlated with promoter-consensus sequences; $r$, artefact of autoradiography. Lanes 1 and 3, no RNA; 2, M. smegmatis RNA $(24 \mu \mathrm{g}) ; 4, M$. tuberculosis RNA $(24 \mu \mathrm{g})$.

from this gene sequence is significantly similar to 113 residues of the carboxyterminal region of UNAcGCT; the BLAST score was $P=20 \times \mathrm{e}^{-23}$ (the lower the score the more certain is the assignment). This enzyme comprises a single polypeptide of approximately 420 amino acids (see for example Ehrt \& Hillen, 1994). As shown in Fig. 2 the gene lying upstream from the $\operatorname{rrn} A_{\mathrm{s}}$ operon of $M$. tuberculosis is homologous with the gene which is located upstream from the $r r A_{\mathrm{f}}$ operon of $M$. smegmatis. Examination of $M$. leprae sequences (Sela \& Clark-Curtiss, 1991) reveals that a gene encoding UNAcGCT is also located upstream from the $\operatorname{rrn} A_{\mathrm{s}}$ operon in that species. In contrast, the gene lying upstream from the $r r n B_{\mathrm{f}}$ operon of $M$. smegmatis is believed to encode tyrosyltRNA synthetase (Predich et al., 1995).

These results confirm our original hypothesis (Ji et al., 1994c) that the $r r n A_{\mathrm{f}}$ and the $r r n A_{\mathrm{s}}$ operons are homologous. The major difference between these two operons is a deletion of $97 \mathrm{bp}$ in the $M$. tuberculosis operon (75 bp in that of $M$. leprae) compared to that of M. smegmatis, as indicated in Fig. 2.

No intrinsic terminators are evident downstream from the UAG stop codons of the ORFs (Fig. 2) indicating that termination of transcription might be rho-dependent. Possible stem-loop structures that could be involved in termination are presented in Fig. 3. In each case a GC-rich stem-loop structure can be formed within 14-21 nucleotides from the UAG codon, suggesting that the trailer regions of the transcripts comprise a minimum of 14-21 nucleotides.

\section{Primer-extension studies}

The RNA fraction of $M$. smegmatis was analysed as described in Methods and the products were identified using appropriate sequencing ladders for the $\operatorname{rrn} A_{\mathrm{f}}$ and $r r n B_{\mathrm{f}}$ operons. Six major products were identified (Fig. 4). Four of the products had identifiable promoter consensus sequences immediately upstream. One of these, giving a product of 160 nucleotides, is on the $r r n B_{\mathrm{p}}$ operon. Predich et al. (1995) also concluded that the $r r n B_{\mathrm{f}}$ operon has a single promoter, on the basis of in vitro transcription 


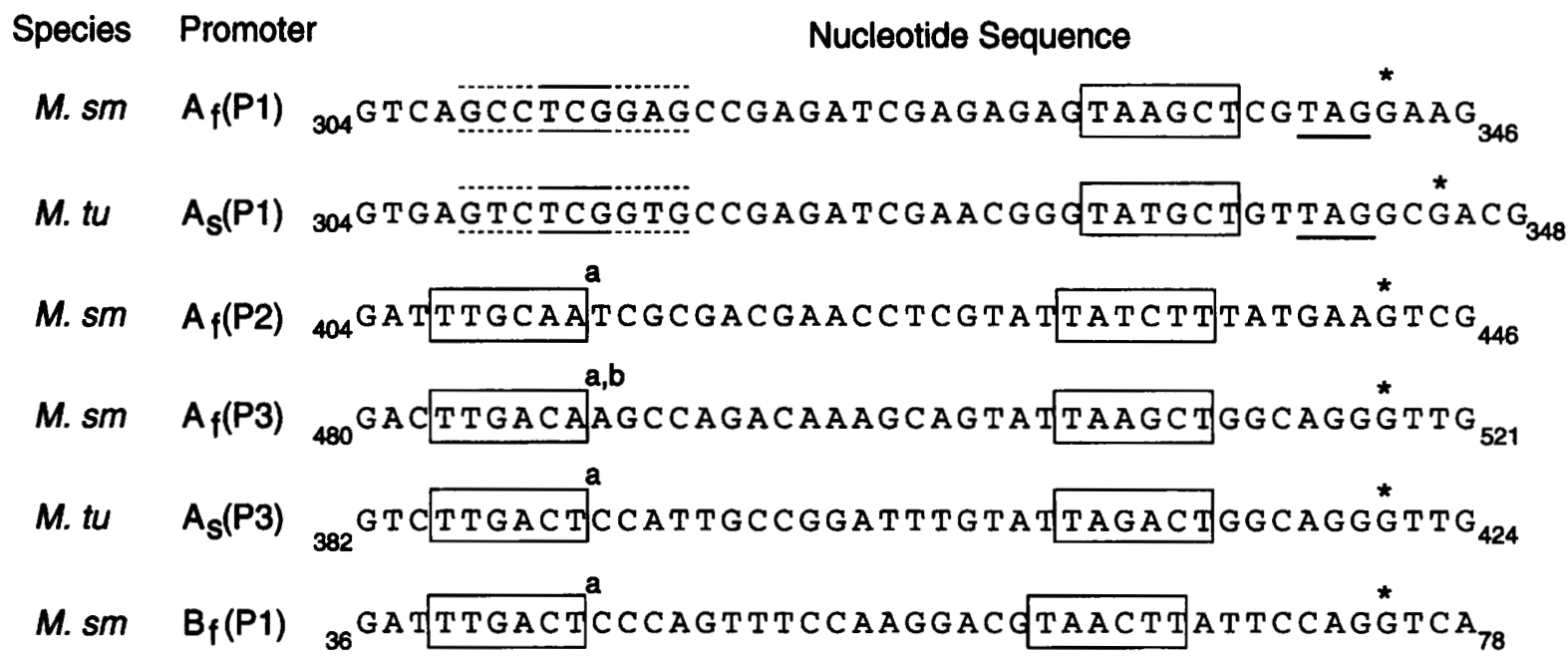

Fig. 5. Comparison of promoter elements of mycobacterial $r r n$ operons. $A_{f}(P 1)$, etc., refer to the $P 1$ promoter of the $r r n A_{f}$ operon, etc.; subscript numbers denote the nucleotide positions given in Fig. 2. Asterisks denote transcription start sites identified by primer extension (Fig. 4). The TAG codons at the $3^{\prime}$-ends of coding regions are underlined. Putative promoter elements ( -35 and -10 boxes) are framed; uncertainty in the identity of -35 boxes is shown by broken lines; a, identified as a -35 box in promoters of $r r n$ operons of B. subtilis (Ogasawara et al., 1983); b, identified as a -35 box for several Streptomyces genes (for review see Strohl, 1992).

studies. Three other putative promoters, giving products of 230,136 and 60 nucleotides (designated P1, P2 and P3, respectively) are on the $r r n A_{\mathrm{f}}$ operon. Two other products, $\mathrm{a}$ and the more prominent $\mathrm{b}(125$ and 98 nucleotides, respectively), have no promoter consensus sequences immediately upstream of them. These could represent novel mycobacterial promoter sequences; it is known that mycobacterial promoters are poorly recognized in Eschericbia coli (Kieser et al., 1986) and little information is available concerning consensus sequences for mycobacterial promoters. Alternatively these products could represent processing sites for $r$ RNA derived from either $r r n A_{\mathrm{f}}$ or $r r n B_{\mathrm{f}}$, or both operons. The $\mathrm{P} 1$ promoter of the $r r n A_{\mathrm{f}}$ operon is located within the coding region for UNAcGCT.

Primer-extension analysis of the $\operatorname{rrn} A_{\mathrm{s}}$ operon of $M$. tuberculosis revealed two products of 134 and 57 nucleotides (Fig. 4); promoter consensus sequences could be associated with both of these transcription start points and they appear to correspond to promoters $\mathrm{P} 1$ and $\mathrm{P} 3$ of the $r r n A_{\mathrm{f}}$ operon of $M$. smegmatis (Fig. 2), providing further evidence of the relatedness of the $\operatorname{rrn} A_{\mathrm{s}}$ and $\operatorname{rrn} A_{\mathrm{f}}$ operons. Two start sites were proposed previously by Verma et al. (1994) for transcription of the $\operatorname{rrn} A_{\mathrm{s}}$ operon of $M$. tuberculosis.

As with $M$. smegmatis, the $\mathrm{P} 1$ promoter of $M$. tuberculosis also lies within the coding region of UNAcGCT. In addition the single promoter identified on the $r r n B_{\mathrm{p}}$ operon is located either within or very close to the transcription region of a gene for tyrosyl-tRNA synthetase (see Fig. 2). In each case, transcription of the gene upstream from the $r r n$ operon would be expected to influence the transcription of the $r r n$ operon from that particular promoter. Unusual locations of promoters are also found elsewhere. Two promoters for elongation factor $\mathrm{Tu}$ of $E$. coli lie within the gene for elongation factor G (Zengel \& Lindahl, 1990), and a review of 139 streptomycete transcription start sites lists at least six promoters which lie within other genes (Strohl, 1992).

The intervals separating the start sites (ts) of the promoters of the $r r n A_{\mathrm{f}}$ operon of $M$. smegmatis are $94 \mathrm{bp}$ between ts(P1) and ts(P2) and 76 bp between ts $(\mathrm{P} 2)$ and ts $(\mathrm{P} 3)$; the start sites $\mathrm{ts}(\mathrm{P} 1)$ and $\mathrm{ts}(\mathrm{P} 3)$ directed by promoters $\mathrm{P} 1$ and $\mathrm{P} 3$ of the $r r n A_{\mathrm{s}}$ operon of $M$. tuberculosis are separated by $77 \mathrm{bp}$. These intervals are comparable to distances separating the two promoters of $\mathrm{rrn}$ operons of Bacillus subtilis [approx. 90 bp (Ogasawara et al., 1983)] and with the intervals between the four promoters of the rrnA operon of Streptomyces coelicolor A3(2) (van Wezel $e t$ al., 1994); namely 180 bp separating $\mathrm{P} 1$ and $\mathrm{P} 2,91 \mathrm{bp}$ separating $\mathrm{P} 2$ and $\mathrm{P} 3$, and 80 bp separating $\mathrm{P} 3$ and $\mathrm{P} 4$.

The differential usage of the three promoters of the $\operatorname{rrn} A_{\mathrm{f}}$ operon of $M$. smegmatis and the two promoters of the $\operatorname{rrn} A_{\mathrm{s}}$ operon of $M$. tuberculosis merits further study. Under the growth conditions used in this study the P2 promoter of the $\operatorname{rrn} A_{\mathrm{f}}$ operon was more active than either the $\mathrm{P} 1$ or the $\mathrm{P} 3$ promoters. In contrast, transcription of the $\operatorname{rrn} A_{\mathrm{s}}$ of $M$. tuberculosis was governed mainly by the P3 promoter, the $\mathrm{P} 2$ promoter being absent from this species, with the P1 promoter playing the minor role. The presence of two or more promoters per operon is a strategy which offers the possibility of increasing the versatility of the operon, for example by enabling the operon to respond over a wide range of growth conditions to the cells' need for rRNA. Another GC-rich Grampositive bacterium, $S$. coelicolor A3(2), has six rrn operons and at least two of them $(r m A$ and $r r n \mathrm{D})$ have four promoters (Baylis \& Bibb, 1988; van Wezel et al., 1994). 
Each of the seven rrn operons of E. coli has two promoters (Gourse et al., 1986; Condon et al., 1992).

The promoter elements identified by means of the primerextension studies are compared in Fig. 5. Apart from the -35 boxes of the P1 promoters of the $\operatorname{rrn} A_{\mathrm{p}}$ and $\operatorname{rrn} A_{\mathrm{s}}$ operons the -35 and -10 motifs are very similar to those reported for promoters of $r r n$ operons of $B$. subtilis (Ogasawara et al., 1983). The P1 promoters of $r r n A_{\mathrm{f}}$ and $r n A_{\mathrm{s}}$ operons are very similar in sequence probably because they also form part of the coding region of a gene for UNAcGCT. A feature of the $\mathrm{P} 2$ and $\mathrm{P} 3$ promoters of the $r r n A_{\mathrm{f}}$ operon and the $\mathrm{P} 3$ promoter of the $r r n A_{\mathrm{s}}$ operon is that the -10 box is preceded by the sequence 5'GTAT3'. There appear to be few features that distinguish elements used by the fast-grower from those used by the slow-grower. It should be noted however that a strongly expressed product was identified in $M$. smegmatis for which no consensus -35 or -10 boxes could be identified; whether this represents a novel promoter sequence or an RNA processing site cannot be distinguished at present.

These studies confirm and extend our previous observations on the relationship between the $r r n$ operons of fast- and slow-growing mycobacteria. More importantly they demonstrate that the two groups have evolved differently not only in terms of the number of operons, but also in terms of their regulation. Experiments currently in progress are designed to investigate the environmental stimuli which affect the differential usage of the multiple promoters and hence should provide novel insights into mechanisms of growth control in these organisms.

\section{ACKNOWLEDGEMENTS}

J.A.G.-y-M. received financial support from the Mexican agencies CONACYT and COFAA \& BDA (IPN). We thank Simon A. Cox for help in preparing the manuscript.

\section{REFERENCES}

Altschul, S. F., Gish, W., Miller, W., Myers, E. W. \& Lipman, D. F. (1990). Basic local alignment search tool. J Mol Biol 215, 403-410.

Baylis, H. A. \& Bibb, M. (1988). Transcriptional analysis of the $16 \mathrm{~S}$ rRNA gene of the $r r n \mathrm{D}$ gene of Streptomyces coelicolor A3(2). Mol Microbiol 2, 569-579.

Bercovier, H., Kafri, O. \& Sela, S. (1986). Mycobacteria possess a surprisingly small number of ribosomal RNA genes in relation to the size of their genome. Biochem Biopbys Res Commun 136, 1136-1141.

Bremer, H. \& Dennis, P. P. (1987). Modulation of chemical composition and other parameters of the cell growth rate. In Escherichia coli and Salmonella typhimurium: Cellular and Molecular Biology, pp. 1527-1542. Edited by F. C. Neidhardt, J. L. Ingraham, K. Brooks Low, B. Magasanik, M. Schaechter \& H. E. Umbarger. Washington, DC: American Society for Microbiology.

Condon, C., Philips, J., Fu, Z.-Y., Squires, C. \& Squires, C. L. (1992). Comparison of the seven ribosomal RNA operons in Eschericbia coli. EMBO J 11, 4175-4185.

Ehrt, S. \& Hillen, W. (1994). UDP- $N$-acetylglucosamine 1carboxyvinyl-transferase from Acinetobacter calcoaceticus. FEMS Microbiol Lett 117, 137-142.
Gonzalez-y-Merchand, J. A., Estrada-Garcia, I., Colston, M. J. \& Cox, R. A. (1986). A novel method for the isolation of mycobacterial DNA. FEMS Microbiol Lett 135, 71-77.

Gourse, R. L., de Boer, H. A. \& Nomura, M. (1986). DNA determinants of $r$ RNA synthesis in E. coli, growth rate dependent regulation, feedback inhibition, upstream activation, antitermination. Cell 44, 197-205.

Ji, Y-e., Colston, M. J. \& Cox, R. A. (1994a). Nucleotide sequence and secondary structures of precursor $16 \mathrm{~S}$ rRNA of slow-growing mycobacteria. Microbiology 140, 123-132.

Ji, Y-e., Kempsell, K., Colston, M. J. \& Cox, R. A. (1994b). Nucleotide sequences of the spacer-1, spacer-2 and trailer regions of the $r m$ operons and secondary structures of precursor 23S rRNA and precursor 5S rRNA of slow-growing mycobacteria. Microbiology 140, 1763-1773.

Ji, Y-e., Colston, M. J. \& Cox, R. A. (1994c). The ribosomal RNA $(r r n)$ operons of fast-growing mycobacteria : primary and secondary structures and their relation to $r r n$ operons of pathogenic slowgrowers. Microbiology 140, 2829-2840.

Kempsell, K. E., Ji, Y-e., Estrada-G, I. C. E., Colston, M. J. \& Cox, R. A. (1992). The nucleotide sequence of the promoter, $16 \mathrm{~S}$ rRNA and spacer region of the ribosomal RNA operon of Mycobacterium tuberculosis and comparison with Mycobacterium leprae precursor rRNA. J Gen Microbiol 138, 1717-1727.

Kieser, T., Loss, M. T., Dale, J. W. \& Hopwood, D. A. (1986). Cloning and expression of Mycobacterium bovis BCG DNA in "Streptomyces lividans". J Bacteriol 168, 72-80.

Liesack, W., Pitulle, C., Sela, S. \& Stackebrandt, E. (1990). Nucleotide sequence of the $16 \mathrm{~S}$ rRNA from Mycobacterium leprae. Nucleic Acids Res 18, 5558.

Liesack, W., Sela, S., Bercovier, H., Pitulle, C. \& Stackebrandt, E. (1991). Complete nucleotide sequence of the Mycobacterium leprae $23 \mathrm{~S}$ and $5 \mathrm{~S}$ rRNA genes plus flanking regions and their potential in designing diagnostic oligonucleotide probes. FEBS Lett 281, 114-118.

Ogasawara, N., Moirya, S. \& Yoshikawa, H. (1983). Structure and organization of rRNA operons in the region of the replication origin of the Bacillus subtilis chromosome. Nucleic Acids Res 11, 6301-6318.

Predich, M., Doukhan, L, Nair, G. \& Smith, I. (1995). Characterization of RNA polymerase and two sigma-factor genes from Mycobacterium smegmatis. Mol Microbiol 15, 355-366.

Rysavy, F. R., Bishop, M. J., Gibbs, G. P. \& Williams, G. W. (1992). U. K. HGMP on line computer service. Comput Appl Biosci 8, 149-154.

Saiki, R. K., Gelfand, D. H., Stoffel, S., Sharf, S. J., Higuchi, K., Horn, G. T., Mullis, K. B. \& Erlich, H. A. (1988). Primer-directed enzymatic amplification of DNA with a thermostable DNA polymerase. Science $239,487-491$.

Sela, S. \& Clark-Curtiss, J. E. (1991). Cloning and characterization of the Mycobacterium leprae putative ribosomal RNA promoter in Eschericbia coli. Gene 98, 123-127.

Strohl, W. R. (1992). Compilation and analysis of DNA sequences associated with apparent streptomycete promoters. Nucleic Acids Res 20, 961-974.

Suzuki, Y., Nagata, A., Ono, Y. \& Yamada, I. (1988). Complete nucleotide sequence of the 16S rRNA gene of Mycobacterium bovis BCG. J Bacteriol 170, 1631-1636.

Verma, A., Kringer, A. K. \& Tyagi, J. S. (1994). Functional analysis of transcription of the Mycobacterium tuberculosis $16 \mathrm{~S} \mathrm{rDNA}$ encoding gene. Gene 148, 113-118. 
Vogelstein, B. \& Gillespie, D. (1979). Preparative and analytical purification of DNA from agarose. Proc Natl Acad Sci USA 76, 615-619.

van Wezel, G. P., Krab, I. M., Douthwaite, S., Bibb, M. J., Vijgenboom, E. \& Bosch, L. (1994). Transcription analysis of the Streptomyces coelicolor A3(2) $\operatorname{rrn} A$ operon. Microbiology 140, 3357-3365.

Winder, F. G. \& Rooney, S. A. (1970). Effects of nitrogenous components of the medium on the carbohydrate and nucleic acid content of Mycobacterium tuberculosis BCG. J Gen Microbiol 63, 29-39.

Zengel, M. \& Lindahl, L. (1990). Mapping of two promoters for elongation factor $\mathrm{Tu}$ within the structural gene for elongation factor G. Biochem Biopbys Acta 1050, 317-322.

Received 29 September 1995; accepted 2 November 1995. 